\title{
Osteoblast compatibility of materials depends on serum protein absorbability in osteogenesis
}

\author{
Kenichi HARIMOTO ${ }^{1}$, Yasuhiro YOSHIDA ${ }^{2}$, Kumiko YOSHIHARA ${ }^{3}$, Noriyuki NAGAOKA ${ }^{4}$, Takuya MATSUMOTO ${ }^{2}$ \\ and Yoh-ichi TAGAWA ${ }^{1}$ \\ ${ }^{1}$ Department of Biomolecular Engineering, Graduate School of Bioscience and Biotechnology, Tokyo Institute of Technology, 4259 B51, Nagatsuta- \\ cho, Midori-ku, Yokohama, 226-8501, Japan \\ ${ }^{2}$ Department of Biomaterials, Okayama University Graduate School of Medicine, Dentistry and Pharmaceutical Sciences, 2-5-1 Shikata-cho, Kita-ku, \\ Okayama, 700-8558, Japan \\ ${ }^{3}$ Leuven BIOMAT Research Cluster, Department of Conservative Dentistry, Catholic University of Leuven, Kapucijnenvoer 7, Leuven, 3000, \\ Belgium \\ ${ }^{4}$ Laboratory for Electron Microscopy, Okayama University Graduate School of Medicine, Dentistry and Pharmaceutical Sciences, 2-5-1 Shikata-cho, \\ Kita-ku, Okayama, 700-8525, Japan \\ Corresponding author, Yoh-ichi TAGAWA; E-mail: ytagawa@bio.titech.ac.jp
}

Titanium has an osseointegrative property, while hydroxyapatite has an osteoconductive property. It remains a matter of controversy among researchers whether hydroxyapatite has higher osteoblast compatibility than titanium. Here, we compared the activities between osteoblasts cultured on titanium and those cultured on hydroxyapatite. An osteoblast-like cell line, MC3T3-E1, was cultured on machined titanium, evaporated titanium, and hydroxyapatite disks to compare the affinity of osteoblasts to each of these materials. The adhesion and proliferation of MC3T3-E1 cells were higher on hydroxyapatite disks than on the other disks. Osteoblast differentiation was not affected by the nature of disks investigated, but calcium was more easily deposited on the hydroxyapatite disks. The amount of absorbed serum proteins detected on hydroxyapatite was greater than that on titanium. In conclusion, our results indicate hydroxyapatite is a more suitable material for osteoblast growth than titanium because of its higher absorption of serum proteins.

Keywords: Osteoblast, Hydroxyapatite, Titanium

\section{INTRODUCTION}

Titanium is widely used for dental implants because of its biocompatibility, mechanical strength and plasticity for prosthetic design ${ }^{1}$. When titanium is implanted into live bone tissue, it actually integrates with the bone. This behavior of osteogenesis is called "osseointegration", as distinguished from "osteoconduction". Osseointegration is defined as direct contact (at the light microscope level) between living bone and an implant ${ }^{2,3}$. Clinical studies have shown that osseointegration in the initial stage is related to the overall clinical success of an implant ${ }^{4}$. There have also been reports that the osseointegration rate of a titanium implant is related to properties of the implant surface ${ }^{5,6)}$. Accordingly, the titanium surface has been topographically or chemically modified to increase the osseointegration $\mathrm{rate}^{7-10)}$. On the other hand, hydroxyapatite is classified as a bioactive material with excellent "osteoconductive" abilities ${ }^{11-14)}$. Osteoconduction is defined as bone growth on a surface that is dependent on the migration of osteogenic cells ${ }^{15,16)}$. Osteoconduction is thus the process by which bone is directed to conform to the surface of a given material ${ }^{1)}$. Therefore, hydroxyapatite is widely used in bone reconstruction ${ }^{17-20)}$. However, hydroxyapatite has a critical disadvantage for use in dental implants because of its low modulus of elasticity and low fracture toughness ${ }^{21)}$.
There have been several reports comparing the behaviors of osteogenic cells on titanium to those on hydroxyapatite. Stromal cells derived from bone marrow cultured on hydroxyapatite showed higher alkaline phosphatase (ALP) activity and expression of osteogenic genes, such as the genes for osteocalcin, osteopontin, and bone sialoprotein, than those from bone marrow cultured on titanium. Mineralized nodule formation was the most predominant on hydroxyapatite. There was no difference in the proliferation of osteoblasts between culture on hydroxyapatite and titanium ${ }^{22}$. MC3T3-E1, the osteoblast-like cell line, cultured on sputtered hydroxyapatite film and hydrothermal treatment, showed significantly increased proliferation and ALP activity compared to MC3T3-E1 cells cultured on titanium ${ }^{23}$. The proliferation and ALP activity of osteoblasts were significantly enhanced on the hydroxyapatitecoated plate compared to those on the titanium-coated plate ${ }^{24)}$. Because the roughness of the material surface influenced the osteoblast activities, attempts have also been made to roughen the titanium surface for improved osteoblast activation. For example, when MC3T3-E1 were cultured on titanium plates roughened by wiretype electric discharge machining or plasma coating, the proliferation and ALP activity were enhanced compared to those on unroughened titanium ${ }^{25,26)}$.

It is still controversial whether hydroxyapatite has higher osteoblast compatibility than titanium. In this 
study, therefore, we compared the osteoblast activities between titanium and hydroxyapatite. As described above, rough surfaces generally enhance the osteoblast compatibility. In order to investigate the effects of the materials themselves on osteoblast compatibility, we used three kinds of disks. One was an evaporated disk with a smooth titanium surface (ti disk), the second was a hydroxyapatite disk with a smooth surface (Ap disk), and the third was a machined titanium disk with a rough surface (TI disk) that was in near-clinical condition.

\section{MATERIALS AND METHODS}

\section{Sample preparation}

Titanium disks (TI, $\varphi 15$ mm×t1, ASTM B348: 97 Grade2; GC, Tokyo, Japan), hydroxyapatite (Ap, Pentax, HAp plate, APP-601, $\varphi 13 \mathrm{~mm} \times \mathrm{t} 2$; Pentax, Tokyo, Japan) and evaporated titanium disks (ti, $\varphi 15 \mathrm{~mm} \times \mathrm{t} 1$, B270superwhite) were used for this study. For preparation of the evaporated ti disk, glass disks ( $\varphi 15 \mathrm{~mm} \times \mathrm{t} 1$, B270superwhite) were first cleaned with alkali detergent, then with distilled water, and finally with isopropyl alcohol using ultrasonic rinsing. Titanium films were then deposited on the cleaned glass disks by an electron beam evaporator (BMC-1100; Shincron, Yokohama, Japan) up to the $40 \mathrm{~nm}$ film thickness. These disks were checked using a field-emission-gun scanning electron microscope (FE-SEM; JEOL JSM-6701F, Jeol, Tokyo, Japan) operated at an accelerating voltage of $10 \mathrm{kV}$. The "Ap" disks were coated with a 3-nm osmium layer using an osmium coater (Meiwa Fosis Neoc-AN, Tokyo, Japan) before FE-SEM was carried out. Surface roughness of each of the three disks was measured using a 3D laser scanning confocal microscope (VK-X200, KEYENCE, Osaka, Japan).

\section{Cell culture}

Cells of the mouse osteoblast-like cell line MC3T3-E1 (RIKEN Cell Bank, Ibaraki, Japan), were cultured in $\alpha$-modified essential medium ( $\alpha$-MEM) supplemented with antibiotics (penicillin/streptomycin; Invitrogen, Tokyo, Japan), $4 \mathrm{mM} \mathrm{L-glutamine} \mathrm{(Invitrogen)} \mathrm{and} \mathrm{10 \%}$ fetal bovine serum (FBS; Nichirei Biosciences, Tokyo, Japan) in $5 \% \mathrm{CO}_{2}$ at $37^{\circ} \mathrm{C}$. The cells were subcultured by treatment with $0.05 \%$ trypsin (Wako, Osaka, Japan) and $20 \mu \mathrm{M}$ ethylenediaminetetraacetic acid (EDTA; Invitrogen).

\section{Cell count}

Each disk was immobilized in a 24 -well plate. Then MC3T3-E1 cells were seeded at $5.0 \times 10^{4}$ cells/well density. At the predetermined time points, the cells were rinsed three times with PBS to remove the nonattached cells. Culture medium containing 10\% WST-8 reagent solution (Dojindo Laboratories, Kumamoto, Japan) was added at $300 \mu \mathrm{L}$ to each well, and the plate was incubated for 1-2 $\mathrm{h}$ at $37^{\circ} \mathrm{C}$. The supernatant was dispensed $100 \mu \mathrm{L}$ to 96 well plate and the absorbance at $450 \mathrm{~nm}$ was measured using a micro-plate reader (Bio-Rad, Tokyo, Japan).

\section{Alkaline phosphatase staining}

An individual disk containing $1 \times 10^{5}$ cells was added to each well of a 24 -well plate. After $24 \mathrm{~h}$, the media were changed and the cells were incubated in culture medium that was supplemented with $50 \mu \mathrm{g} / \mathrm{mL}$ L-ascorbic acid (Wako) and $10 \mathrm{mM} \beta$-glycerophosphate (Wako). The day that the cells were changed to this specific medium was considered day 0 . The medium was changed twice a week.

The cells on each disk were washed after culturing for 2 weeks in differentiation medium. Then the disks were incubated for $30 \mathrm{~min}$ in a solution of alkaline phosphatase substrate produced using an Alkaline Phosphatase Substrate Kit III (Vector Laboratories, Burlingame, CA). The solution was removed and the cells were washed with PBS three times. ALP-positive cells were stained blue.

\section{Alizarin Red S staining}

The cells on each disk were washed after 4 weeks of culture in differentiation medium. Then the cells were fixed with ethanol and stained with 1\% Alizarin Red S (Wako) in order to visualize the calcium deposits on cells. Alizarin Red S binds selectively to calcium; the stained material appears dark red.

\section{Quartz crystal microbalance (QCM) measurements}

QCM measurements were made using a Q-SENSE D300 system (Q-Sence, Gothenburg, Sweden). FBS was diluted to $0.1 \%$ and $0.5 \mathrm{~mL}$ of the diluted solution was applied to a sensor chamber. Upon interaction of serum molecules with the surface of a sensor crystal, changes in the resonance frequency, $\Delta f$, related to mass, were measured with a time resolution no later than 1 $\mathrm{s}$. The measurement data of $\mathrm{F}$ were acquired at several harmonics $(15,25$, and $35 \mathrm{MHz})$ simultaneously. All measurements were performed at $37^{\circ} \mathrm{C}$, to within $0.1^{\circ} \mathrm{C}$.

\section{RESULTS}

The surfaces of each of the three disk types, "TI," "ti" and "Ap," were randomly observed by SEM and the roughness was measured by a 3D laser scanning confocal microscope. As shown in Fig.1, the surface of the TI disk exhibited asperity, but the ti and Ap surfaces were flat indicating that TI was rougher than the other two kinds of disks in this study. The arithmetic mean value, $R \mathrm{a}$, of TI was $0.13 \mu \mathrm{m}$, and that of ti and Ap was $0.01 \mu \mathrm{m}$. MC3T3-E1 cells, an osteoblast-like cell line, were seeded at $1 \times 10^{5}$ cells/plate on each disk in the serum-containing medium. As shown in Fig. 2, the number of adhered cells was counted by measuring WST- 8 activity levels at 1,2 , 3,7 , and $10 \mathrm{~h}$ after seeding. The adhered cell number was increased in a time-dependent manner, but was not significantly different between the two smooth disks (Fig. 2). In order to rule out the effect of biomolecules contained in serum and to more clearly compare the cell adhesion property of the materials, MC3T3-E1 cells were seeded onto each disk in the serum-free medium 
(a)
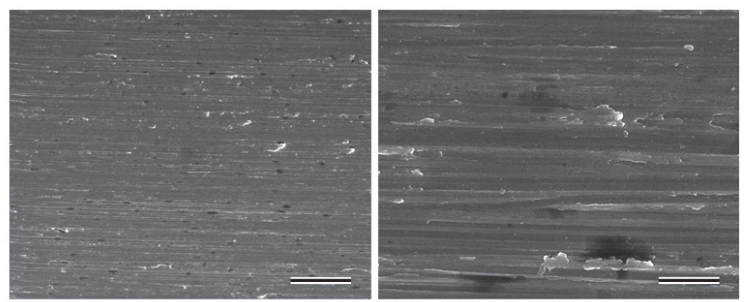

(b)
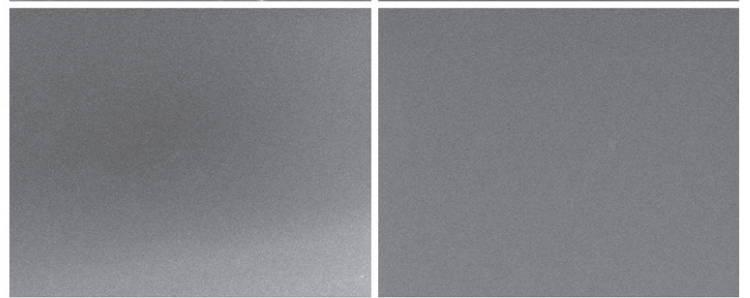

(c)
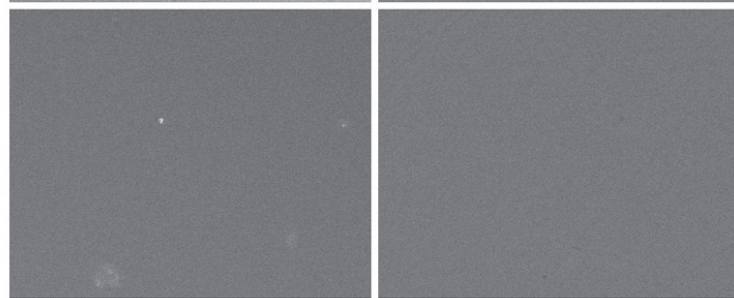

Fig. 1 Surface properties of each disk.

SEM images of the three kinds of disks. The scale bar indicates $20 \mu \mathrm{m}$ in the left-side panels and $2 \mu \mathrm{m}$ in the right-side panels. (a) The Ti bulk (machining) disk (TI); (b) the Ti (evaporation) disk (ti); (c) the Ap bulk (polishing) disk (Ap).

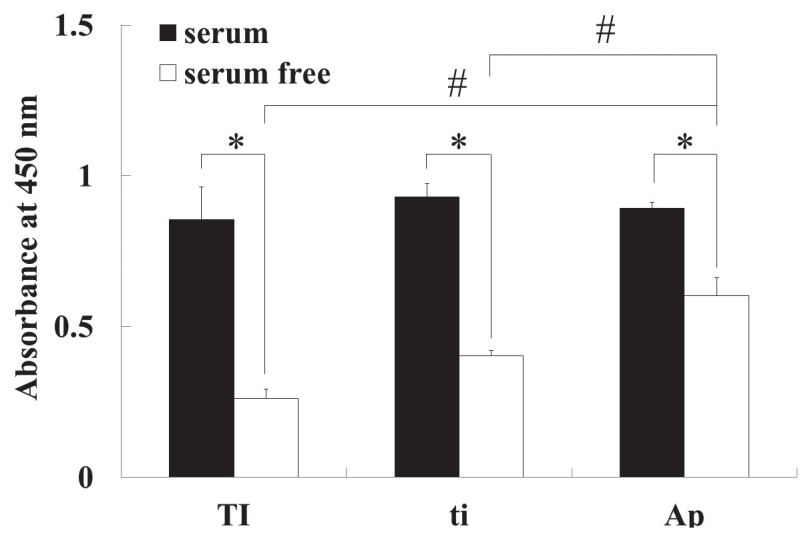

Fig. 3 Cell adhesion assays with and without serum.

Cells were seeded and cultured for $6 \mathrm{~h}$ in serumcontaining medium or serum-free medium. The adhered cell number was measured by WST- 8 activity. The graph shows the $450 \mathrm{~nm}$ absorbance of WST-8, indicating the number of cells attached to each material. Black and white bars indicate cell adhesion in the serum-containing medium or serum-free medium, respectively. Data are expressed as the mean $\pm \operatorname{SEM}$ ( $n=3$ for each plate). Analysis of variance (ANOVA) was performed, and significant differences between plates were determined using the Tukey test $\left({ }^{*} p<0.01\right.$ vs serum-containing medium, $\# p<0.05$ vs TI and ti).

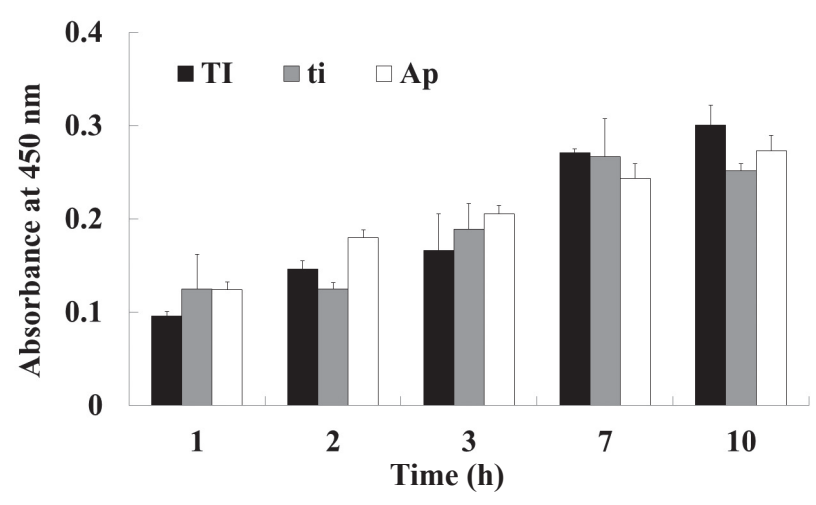

Fig. 2 Time course of cell adhesion.

Cells were seeded on each material, and the number of attached cells was measured at each time point indicated in the graph. The graph shows timedependent cell attachment. Black, gray, and white bars indicate attachment on a machined titanium disk (TI), a titanium evaporated disk (ti), and a hydroxyapatite disk (Ap), respectively. Data are expressed as the mean \pm SEM. $(n=3$ for each plate). Analysis of variance (ANOVA) was performed. No significant differences in any of these parameters were observed among the three disks tested.

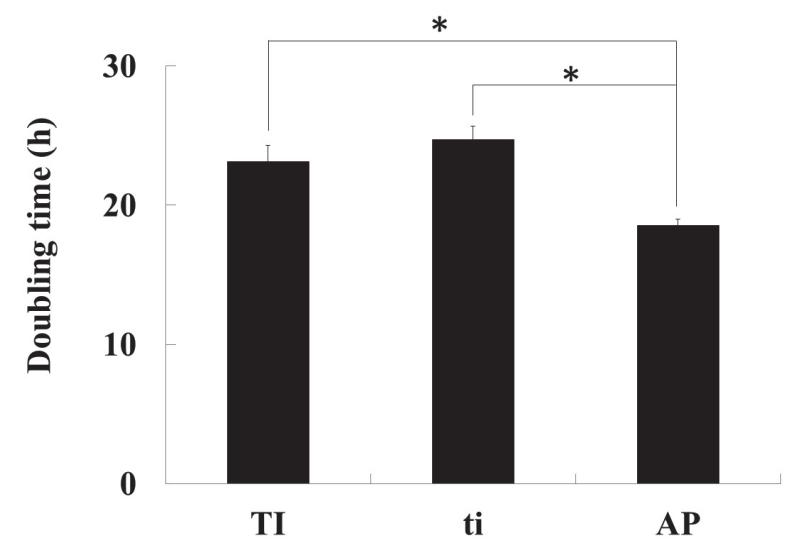

Fig. 4 Cell proliferation assay.

MC3T3-E1 was cultured on each material, and the number of cells was counted every day. The proliferation ratio was plotted at 24 -h intervals, and normalized against the initial counted number. The doubling time of each cell was calculated by plotting the logarithmic average of the cell number. Data are expressed as the mean $\pm \operatorname{SEM}(n=3$ for each disk). Analysis of variance (ANOVA) was performed, and significant differences disks were determined using the Tukey test $\left({ }^{*} p<0.01\right.$ vs TI and ti). 
and WST- 8 activity was measured at $10 \mathrm{~h}$. The adhered cell number was significantly higher on the Ap than on the ti disk in the serum-free medium, while no difference was observed in the serum-containing medium. The adhered cell number on both the Ap and ti disks was smaller in the serum-free medium than in the serum- containing one (Fig.3). The cell adhesion dynamics on a rough titanium surface were also investigated on TI, but no difference could be detected among the three kinds of disks. The number of adhered cells on the TI disk was also smaller than that on the Ap disk.

MC3T3-E1 cells were seeded at $1 \times 10^{4}$ cells/disk, (a)

TI
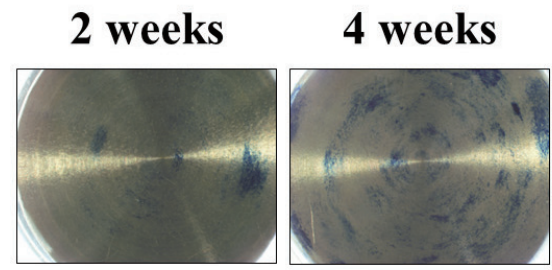

ti
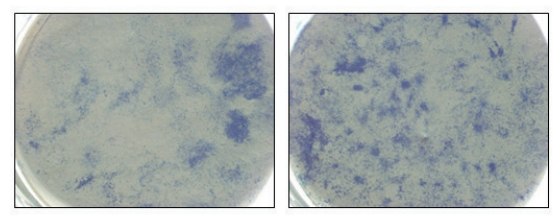

Ap
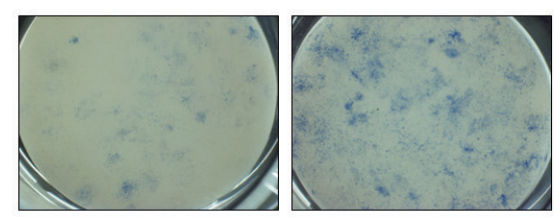

(b)
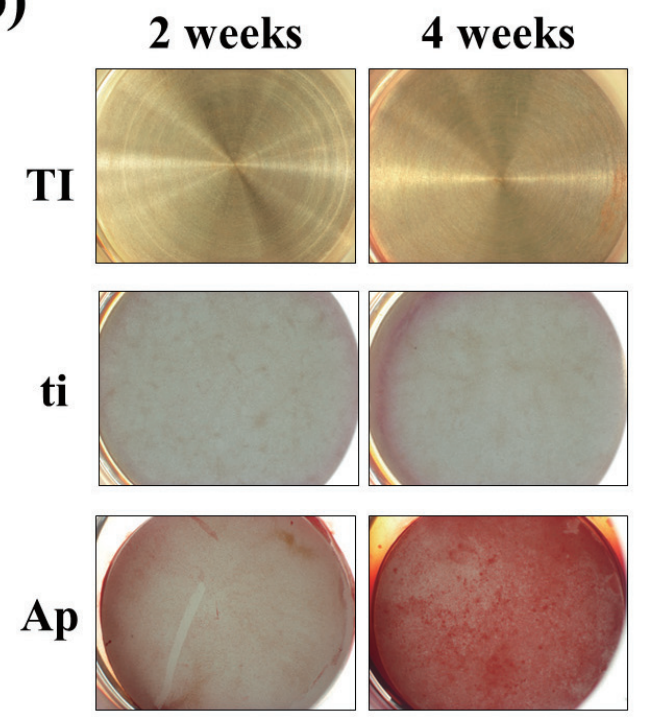

Fig. 5 Osteoblast differentiation and mineralization.

(a) ALP activity of MC3T3-E1 cells on each disk: Osteoblast differentiation was observed by staining ALP-positive cells (blue). The MC3T3-E1 cells on each material were cultured in differentiation-inducing medium. ALP staining was performed after 2 and 4 weeks. (b) Alizarin red S staining: Osteoblast mineralization was observed by staining ALP-positive cells. MC3T3-E1 cells grown on each material were cultured in differentiation-inducing medium. Alizarin red staining was performed after 2 or 4 weeks; the red region indicates calcium deposition.

\section{(a)}

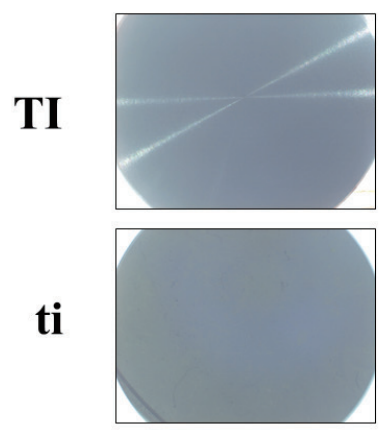

Ap

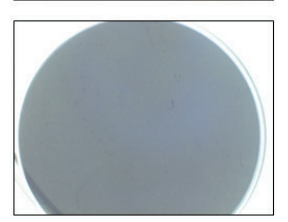

(b)

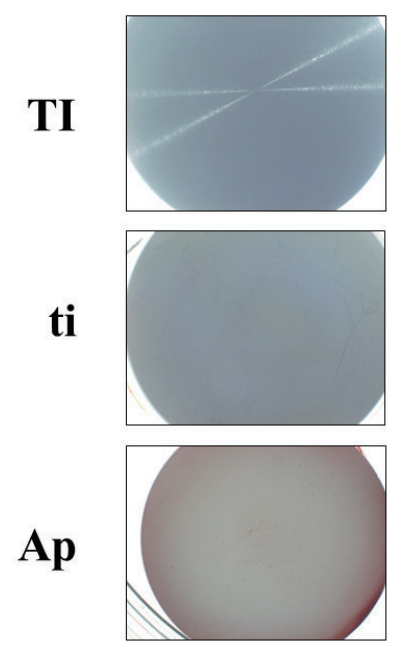

Fig. 6 Three kinds of disks (TI, ti and Ap) without MC3T3-E1 cells was stained by a solution of alkaline phosphatase substrate produced using an Alkaline Phosphatase Substrate Kit III (a) and by Alizarin red S (b). 


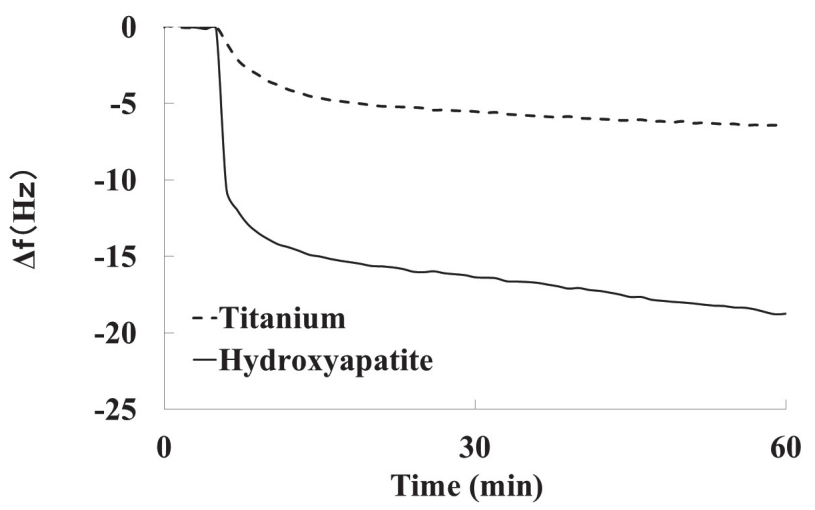

Fig. 7 Absorbability of serum proteins on titanium and hydroxyapatite.

Serum molecular absorption on titanium or hydroxyapatite was measured by QCM measurements. Changes in the resonance frequency, $\Delta f$, were related to the attached mass. The solid line indicates the results for the hydroxyapatite sensor, and the dotted line indicates the results for the titanium sensor.

after which the number of the cells gradually increased on all plates for up to 7 days. The cell proliferation ratio was determined by the number of adherent cells on the first day, and the doubling time was calculated as the ratio of adherent cells at the first day to adherent cells at 2-4 days. The results showed that MC3T3-E1 cells cultured on the Ap disk took less time to duplicate than those cultured on the ti or TI disk (Fig.4).

Osteoblast progenitor cells were differentiated to osteoblasts after the cells reached confluence. The addition of $50 \mu \mathrm{g} / \mathrm{mL}$ L-ascorbic acid and $10 \mathrm{mM}$ $\beta$-glycerophosphate into the medium allows MC3T3-E1 cells to be differentiated into alkaline phosphatasepositive cells, and these differentiated cells could be detected two weeks after such treatment on ti and Ap disks (Fig.5 (a)). Four weeks after the addition of L-ascorbic acid and $\beta$-glycerophosphate, calcium deposition could also be observed on both plates, but more calcium was deposited on the Ap disk than the ti disk (Fig.5 (b)). Although calcium is a composition of hydroxyapatite, an Ap disk itself was not stained by Alizarin red S (Fig.6). The osteoblast differentiation and mineralization on the Ap disk were also higher than those on the TI disk. These results suggest that the characteristics of hydroxyapatite are better for osteogenesis by MC3T3-E1 cells than the characteristics of titanium, even if the titanium has a rough surface.

The amount of absorbed serum proteins on the titanium or hydroxyapatite sensor was quantified by a QCM. As can be seen in Fig. 7, the value of the frequency decreased after applying $0.1 \%$ FBS solution into each sensor module, with the decrease being particularly immediate on the hydroxyapatite sensor. The decrease in the frequency value, $\Delta f$, was much larger on the hydroxyapatite than on the $\mathrm{Ti}$ sensor. These results suggest that a larger amount of serum protein was absorbed on the hydroxyapatite sensor compared to the Ti sensor.

\section{DISCUSSION}

Osteogenesis is a biomineralization process regulated by multiple organic molecules that are secreted from osteoblasts. During this process, osteoblasts could be divided into three stages ${ }^{27)}$. The first stage is the proliferation stage. At the beginning of bone formation, pre-osteoblasts adhere to the surface and proliferate there, and these cells express type I collagen and form basic extracellular matrix (ECM). The second stage is the differentiation stage. ALP was expressed at the end of the proliferation stage and increased at the differentiation stage. Pre-osteoblasts differentiate into osteoblasts under the regulation of growth factors, and ECM was maturated at this stage. The third stage is the mineralization stage. During the mineralization stage, the expression of proteins relative to mineralization is increased, and these proteins are secreted into the ECM to promote calcium accumulation. In this study, we compared osteoblast compatibility between titanium and hydroxyapatite at these stages using smooth surface disks designated "ti" and "Ap." The results of the cell adhesion experiments shown in Fig.2 and Fig. 3 suggest that the adhesion of MC3T3-E1 cells did not depend on the materials under the serum-present condition, but hydroxyapatite was more suitable for osteoblast adhesion than titanium under the serum-free condition. Only a few adhesion molecules were present in the serum-free medium, because the numerous molecules related to cell adhesion that are present in serum were largely absent. Hydroxyapatite could be considered an adequate material for cell adhesion even it is present in very low concentrations of cell adhesion molecules. The shorter doubling time of MC3T3-E1 cells on the Ap than on the ti disk (Fig.4) indicated that the cell growth was promoted by hydroxyapatite rather than titanium. Taking these results together, it was suggested that hydroxyapatite has more osteoblast compatibility in the proliferation stage. Alkaline phosphatase (ALP) is a marker of osteoblast differentiation ${ }^{28)}$; ALP activity is commonly used as an indicator of calcification in the matrixmaturation phase, which initiates actual bone formation. In this study, the MC3T3-E1 cells differentiated into ALP-positive cells on the ti and Ap disks two weeks after the addition of L-ascorbic acid and $\beta$-glycerophosphate. The results on the ALP activity (Fig.5) demonstrate that the in vitro osteoblast differentiation was normal on both materials and suggest that hydroxyapatite and titanium do not affect the differentiation stage. Alizarin red $\mathrm{S}$ is also widely used for visualization of cell calcification ${ }^{28)}$. Four weeks after induction, calcium deposition could be observed on all disks. The results from the Alizarin red $\mathrm{S}$ staining (Fig.5) demonstrate that calcium was readily deposited on osteoblast cultured on hydroxyapatite. The results of ALP activity and Alizarin red S suggest that hydroxyapatite supports osteoblasts differentiation and 
promote them to switch to the mineralization stage, or that titanium arrested osteoblasts differentiation and suppressed them to move into the mineralization stage. Further studies are needed to confirm the critical factor. The results also suggest that hydroxyapatite not only by affecting osteoblasts but also through the interaction of calcium with materials in the mineralization stage because of its absorbent characteristic.

Osteoblast behaviors such as adhesion, proliferation, differentiation and mineralization are affected by proteins contained in serum. This is why we hypothesized that the high biocompatibility of certain materials may be due to the large amounts of proteins absorbed on the surface. The QCM technique is among the most highly sensitive and practical tools for in situ measurement of macromolecule absorption on the material surface and analysis of molecular conformational change ${ }^{29)}$. The results of QCM measurement shown in Fig.7 indicated that hydroxyapatite can absorb more serum proteins than titanium. Our results also conformed to a report that hydroxyapatite absorbed more cell attachment proteins such as fibronectin, and vitronectin than pure titanium of the same roughness ${ }^{30)}$. Because hydroxyapatite has stronger absorbability than titanium, the Ap disk could have gathered cell adhesion molecules on its surface even it was in serum-free medium, so that more cells adhered on the Ap disk than on the ti disk. The reason why Ap promote osteoblast growth shown in Fig.4 and differentiation in Fig.5 also could be considered as the growth signal proteins contained in serum ${ }^{31)}$ were absorbed more on Ap surface than ti surface.

In this study we also cultured MC3T3-E1 cells on TI to compare the potential of materials to affinity to osteoblast. According to SEM images and the confocal microscope analysis, the roughness of ti is nearly to the roughness of Ap and machined titanium disks have rougher surfaces than ti. Surface roughness is known to be an important factor for cell adhesion, proliferation, and differentiation ${ }^{32-34)}$. In general, it is said that a rough surface promotes cell adhesion and cell proliferation on titanium $^{35}$ ) and that the surface roughness of titanium alters osteoblast proliferation and differentiation ${ }^{34)}$. A titanium disk with a rough surface (TI) would be expected to show higher performance than one with a smooth surface (ti). However, TI still has not reached the osteoblast compatibility of Ap. According to the results of our biological experiment shown in Fig.2 and Fig.5, the roughness did not significantly affect osteoblast behavior on titanium. The reason for this finding may have been that there exists a suitable range of roughness for cell adhesion, and the TI disk used in this study was outside of that range. In addition, the pure titanium has oxidation layer on its surface, and ti may be amorphous. This difference may affect the molecular absorption related to cell adhesion and result in the adhesion property. In the case of hydroxyapatite, the adhesion and proliferation of osteoblasts has also been shown to depend on the surface roughness ${ }^{33)}$. Ap used in our study only has smooth surface but its osteoblast compatibility was higher than TI, rough surface of titanium. Considering all these result together, it can be said that hydroxyapatite was more compatible with osteoblasts than titanium.

It has been reported that the high potential of osseointegration of titanium may be due to the apatite formation on the titanium surface ${ }^{36)}$. There are two findings which lend support to this hypothesis. One is that titanium easily formed apatite when placed into Simulated Body Fluid ${ }^{37}$. The other is that apatite can be in place of bone tissue by osteoconduction ${ }^{38)}$. According to our results, apatite was easier to deposit calcium, and apatite also seemed to have an ability to promote ALP activity. Our results also indicate hydroxyapatite is more compatibility to osteoblast than titanium, and the high compatibility of hydroxyapatite depends on its high absorbability. Formation of apatite on titanium may gather plenty serum proteins such as adhesion molecular and growth factors on its surface, and let osteoblast easily come to titanium surface and promote osteogenesis on its surface. Hydroxyapatite coating on titanium was examined to enhanced osseointegration of implant ${ }^{39)}$, but it has not get successful results because of the crack appearance at the interface between titanium and hydroxyapatite. Our results give a view point for implant materials development that modification of protein absorbability on titanium surface may be the important factor to develop high potential materials for osseointegration.

\section{CONCLUSION}

In conclusion, our results indicate apatite has a higher affinity for osteoblasts than titanium. This was found to be due not to surface roughness but rather intrinsic properties of the materials, such as protein absorption ability. Although titanium has been successfully used as an implant material in the clinic for quite a long time, this study suggests that the reason titanium better promotes osseointegration is related to the high compatibility of apatite which may be formed on the titanium surface.

\section{ACKNOWLEDGMENTS}

This study was supported by a Grant-in-Aid for Scientific Research (B) [No. 21300178] from the Japanese Society for the Promotion of Science (JSPS) and a Grant-inAid for Scientific Research on Innovative Areas [No. 23119003] from the Ministry of Education, Culture, Sports, Science and Technology (MEXT) of Japan.

\section{REFERENCES}

1) Yang F, Wen-Jing-Dong, He FM, DE XX, Zhao SF, Yang GL. Osteoblast response to porous titanium surfaces coated with zinc-substituted hydroxyapatite. Oral Surg Oral Med Oral Pathol Oral Radiol Endod 2011 (in press).

2) Albrektsson T, Johansson C. Osteoinduction, osteoconduction and osseointegration. Eur Spine J 2001; 10 Suppl 2: S96101.

3) Albrektsson T, Brånemark PI, Hansson HA, Lindström J. Osseointegrated titanium implants. Requirements for 
ensuring a long-lasting, direct bone anchorage in man. Acta Orthop Scand 1981; 52: 155-170

4) Pye AD, Lockhart DE, Dawson MP, Murray CA, Smith AJ. A review of dental implants and infection. J Hosp Infect 2009; 72: 104-110

5) Mendonça G, Mendonça DB, Aragão FJ, Cooper LF. Advancing dental implant surface technology-from micronto nanotopography. Biomaterials 2008; 29: 3822-3835.

6) Cooper LF. Biologic determinants of bone formation for osseointegration: clues for future clinical improvements. J Prosthet Dent 1998; 80: 439-449.

7) Nanci A, Wuest JD, Peru L, Brunet P, Sharma V, Zalzal S, McKee MD. Chemical modification of titanium surfaces for covalent attachment of biological molecules. J Biomed Mater Res 1998; 40: 324-335.

8) Boyan BD, Schwartz Z, Hambleton JC. Response of bone and cartilage cells to biomaterials in vivo and in vitro. J Oral Implantol 1993; 19: 116-122.

9) Schwartz Z, Swain LD, Marshall T, Sela J, Gross U, Amir D, Muller-Mai C, Boyan BD. Modulation of matrix vesicle enzyme activity and phosphatidylserine content by ceramic implant materials during endosteal bone healing. Calcif Tissue Int 1992; 51: 429-437.

10) Stanford CM, Johnson GK, Fakhry A, Gratton D, Mellonig JT, Wanger W. Outcomes of a fluoride modified implant one year after loading in the posterior- maxilla when placed with the osteotome surgical technique. Appl Osseointegration Res 2006; 5: 50-55

11) Fujibayashi S, Neo M, Kim HM, Kokubo T, Nakamura T. Osteoinduction of porous bioactive titanium metal. Biomaterials 2004; 25: 443-450.

12) Kokubo T. Bioactive glass ceramics: properties and applications. Biomaterials 1991; 12: 155-163.

13) Hench LL. Bioactive materials: the potential for tissue regeneration. J Biomed Mater Res 1998; 41: 511-518.

14) Neo M, Kotani S, Nakamura T, Yamamuro T, Ohtsuki C, Kokubo T, Bando Y. A comparative study of ultrastructures of the interfaces between four kinds of surface-active ceramic and bone. J Biomed Mater Res 1992; 26: 1419-1432.

15) Albrektsson T, Johansson C. Osteoinduction, osteoconduction and osseointegration. Eur Spine J 2001;10: 96-101.

16) Mendes VC, Moineddin R, Davies JE. Discrete calcium phosphate nanocrystalline deposition enhances osteoconduction on titanium-based implant surfaces. J Biomed Mater Res A 2009; 90: 577-585.

17) $\mathrm{Hu} \mathrm{X}$, Shen H, Shuai K, Zhang E, Bai Y, Cheng Y, Xiong $\mathrm{X}$, Wang S, Fang J, Wei S. Surface bioactivity modification of titanium by $\mathrm{CO}_{2}$ plasma treatment and induction of hydroxyapatite: In vitro and in vivo studies. Appl Surf Sci 2011; 257: 1813-1823.

18) Cooper LF, Zhou YS, Takebe J, Guo JL, Abron A, Holmen A, Ellingsen JE. Fluoride modification effects on osteoblast behavior and bone formation at $\mathrm{TiO}_{2}$ gritblasted c.p. titanium endosseous implants, Biomaterials 2006; 27: 926-936.

19) Wen $C$, Guan $S$, Peng L, Ren $C$, Wang $X, H u$ Z. Characterization and degradation behavior of AZ31 alloy surface modified by bone-like hydroxyapatite for implant applications. Appl Surf Sci 2009; 255: 6433-6438

20) Denissen HW, de Groot K, Makkes PC, van den Hooff A, Klopper PJ. Tissue response to dense apatite implants in rats. J Biomed Mater Res 1980; 14: 713-721.

21) Reis ECC, BorgesAPB, FonsecaCC, MartinezMMM, EleotérioRB, Morato GO, Oliveria PM. Biocompatibility, osteointegration, osteoconduction, and biodegradation of a hydroxyapatite-polyhydroxybutyrate composite. Braz Arch Biol Technol 2010; 53: 817-826.

22) Ozawa S, Kasugai S. Evaluation of implant materials (hydroxyapatite, glass-ceramics, titanium) in rat bone marrow stromal cell culture. Biomaterials 1996; 17: 23-29.

23) Ozeki K, Aoki H, Fukui Y. Dissolution behavior and in vitro evaluation of sputtered hydroxyapatite films subject to a low temperature hydrothermal treatment. J Biomed Mater Res A 2006; 76: 605-613.

24) Hatano $K$, Inoue $H$, Kojo $T$, Matsunaga $T$, Tsujisawa $T$, Uchiyama C, Uchida Y. Effect of surface roughness on proliferation and alkaline phosphatase expression of rat calvarial cells cultured on polystyrene. Bone 1999; 25: 439445 .

25) Albrektsson T, Brånemark PI, Hansson HA, Lindström J. Osseointegrated titanium implants: Requirements for ensuring a long-lasting, direct bone-to-implant anchorage in man. Acta Orthop Scand 1981; 52: 155-170.

26) Jarcho M. Calcium phosphate ceramics as hard tissue prosthetics. Clin Orthop 1981; 157: 259-278.

27) Quarles LD, Yohay DA, Lever LW, Caton R, Wenstrup RJ. Distinct proliferative and differentiated stages of murine MC3T3-E1 cells in culture: an in vitro model of osteoblast development. J Bone Miner Res 1992; 7: 683-692.

28) Komori T, Yagi H, Nomura S, Yamaguchi A, Sasaki K, Deguchi K, Shimizu Y, Bronson RT, Gao YH, Inada M, Sato M, Okamoto R, Kitamura Y, Yoshiki S, Kishimoto T. Targeted disruption of Cbfa1 results in a complete lack of bone formation owing to maturational arrest of osteoblasts. Cell 1997; 89: 755-764.

29) Monkawa A, Ikoma T, Yunoki S, Yoshioka T, Tanaka J, Chakarov D, Kasemo B. Fabrication of hydroxyapatite ultrathin layer on gold surface and its application for quartz crystal microbalance technique. Biomaterials 2006; 27: 5748-5754.

30) Kilpadi KL, Chang PL, Bellis SL. Hydroxylapatite binds more serum proteins, purified integrins, and osteoblast precursor cells than titanium or steel. J Biomed Mater Res 2001; 57: 258-267.

31) Okazaki R, Ikeda K, Sakamoto A, Nakano T, Morimoto K, Kikuchi T, Urakawa K, Ogata E, Matsumoto T. Transcriptional activation of c-fos and c-jun protooncogenes by serum growth factors in osteoblast-like MC3T3-E1 cells. J Bone Miner Res 1992; 7:1149-1155.

32) Martin JY, Schwartz Z, Hummert TW, Schraub DM, Simpson J, Lankford J Jr, Dean DD, Cochran DL, Boyan BD. Effect of titanium surface roughness on proliferation, differentiation, and protein synthesis of human osteoblast-like cells (MG63). J Biomed Mater Res 1995; 29: 389-401.

33) Deligianni DD, Katsala ND, Koutsoukos PG, Missirlis YF. Effect of surface roughness of hydroxyapatite on human bone marrow cell adhesion, proliferation, differentiation and detachment strength. Biomaterials 2001; 22: 87-96.

34) Martin JY, Schwartz Z, Hummert TW, Schraub DM, Simpson J, Lankford J Jr, Dean DD, Cochran DL, Boyan BD. Effect of titanium surface roughness on proliferation, differentiation, and protein synthesis of human osteoblast-like cells (MG63). J Biomed Mater Res 1995; 29: 389-401.

35) Lampin M, Warocquier-Clérout, Legris C, Degrange M, SigotLuizard MF. Correlation between substratum roughness and wettability, cell adhesion, and cell migration. J Biomed Mater Res 1997; 36:99-108

36) Kokubo T, Miyaji F, Kim HM, Nakamura T. Spontaneous formation of bonelike apatite layer on chemically treated titanium metals. J Am Ceram Soc 1996; 79: 1127-1129

37) Li P, Ducheyne P. Quasi-biological apatite film induced by titanium in a simulated body fluid. J Biomed Mater Res 1998; 41: 341-348.

38) Tanahashi M, Kokubo T, Nakamura T, Katsura Y, Nagano M. Ultrastructural study of an apatite layer formed by a biomimetic process and its bonding to bone. Biomaterials 1996; 17: 47-51.

39) Franco Rde L, Chiesa R, Beloti MM, de Oliveira PT, Rosa AL. Human osteoblastic cell response to a Ca- and P-enriched titanium surface obtained by anodization. J Biomed Mater Res A 2009; 88: 841-848. 